\title{
Fatigue strengthening of riveted girders in a historic railway metallic bridge in Switzerland using pre-stressed un-bonded CFRP laminates
}

\author{
E. Ghafoori \& M. Motavalli \\ Empa, Swiss Federal Laboratories for Materials Science and Technology, Duebendorf, Switzerland
}

A. Herwig

Engineering Office Conzett Bronzini Partner AG, Chur, Switzerland

A. Nussbaumer

EPFL, Swiss Federal Institute of Technology Lausanne, Steel Structure Laboratory, Lausanne, Switzerland

G.S. Prinz

University of Arkansas, Department of Civil Engineering, Fayetteville, AR, USA

M. Fontana

ETH Zürich, Institute of Structural Engineering, Zurich, Switzerland

ABSTRACT: In this paper, the applicability of the constant life diagram (CLD) methodology for fatigue strengthening of metallic members is described. The CLD methodology is a method that uses the combined effect of alternating stress, mean stress and material properties to predict the material life-time under high-cycle fatigue loading. The method could be used most efficiently to improve resistance to crack initiation in 'safelife' members, which is, in fact, a preventive fatigue strengthening approach. The method can be used to increase the fatigue safety margins of un-cracked metallic members. Furthermore, an innovative pre-stressed unbonded reinforcement (PUR) system has been developed and patented. The advantages of the developed PUR system are: applicable to unsmooth surfaces (e.g., riveted or corroded), fast on-site installation (i.e., no glue and no surface preparation), no damage on metallic member (no weld, hole or grinding) and adjustable carbon fiberreinforced polymer (CFRP) pre-stress level. The system can be easily disassembled and removed, if necessary, which makes it suitable for historical bridges as a temporary or permanent retrofit technique. Lastly, this paper presents details about fatigue strengthening of riveted girders in a 120-year-old railway (wrought iron) bridge using the PUR system such that the requirements of the CLD approach are fulfilled.

\section{INTRODUCTION}

\subsection{State of existing metallic bridges}

The US Department of Transportation revealed in 2008 that nearly $27 \%$ of the existing railway bridges in the US are structurally or functionally deficient. Metallic bridges were among the groups most recommended for improvement. More than $43 \%$ of the total number of functionally deficient bridges are made from metal. Corrosion, lack of proper maintenance, and fatigue sensitive details are major problems in such metallic bridges. In addition, many of these bridges need to be upgraded to carry larger loads and more traffic. To combat this worldwide problem, bridge authorities typically search for retrofit solutions rather than replacing deficient bridges entirely. The expenses of strengthening are often far less than the expenses of demolishing and replacing deficient bridges. Furthermore, retrofitting often requires less time and interruption in bridge serviceability. There is a need for research studies that develop strengthening solutions for existing aging metallic structures, especially bridges, to prevent disastrous structural failures.

\subsection{Pre-stressed un-bonded retrofit (PUR) systems}

Carbon fiber reinforced polymer (CFRP) materials have been used for many retrofit solutions due to their high strength-to-weight ratio, high corrosion resistance and excellent fatigue performance (AlEmrani and Kliger 2006b, Colombi et al. 2003a, Colombi et al. 2003b, Dawood et al. 2007, ElHacha and Aly 2013, Linghoff et al. 2010, Nozaka et al. 2005, Rizkalla et al. 2008, Saadatmanesh et al. 1989, Schnerch et al. 2007, Schnerch et al. 2006, Smith and J.G. 2001, Tavakkolizadeh and Saadatmanesh 2003, Wu et al. 2013, Zhao et al. 2014). Nevertheless, strengthening using CFRP plates often cannot considerably increase the stiffness of metallic bridge girders because the thicknesses of the plates are typically much smaller than the dimensions of the girders. Therefore, the stress range, which is the only parameter that most structural standards use for fatigue verification, is not reduced considerably, and thus the use of CFRP plates seems to be inefficient for fatigue strengthening. Having said that, pre-stressed CFRP plates can apply an appreciable compressive stress to the metallic detail and can substantially increase the fatigue life of the member. CFRP plates typically have been ap- 
plied to metallic members using glues, which transfer the stresses from the metallic substrate to the CFRP plate through the adhesive layer by interfacial shear stresses (Al-Emrani and Kliger 2006b, AlEmrani and Kliger 2006a, Al-Emrani and Kliger 2009, Benachour et al. 2008, Czaderski and Rabinovitch 2010, Dawood and Rizkalla 2010, Dawood et al. 2007, Ghafoori 2013, Ghafoori and Motavalli 2013a). However, the positive effect of pre-stressing is assumed to be more significant than the positive effect of the bond. Thus, it can be concluded that, by developing a pre-stressed un-bonded CFRP strengthening system, the advantages of the compressive force (introduced by the pre-stressed CFRP plates) are achieved; however, concerns related to CFRP-to-steel bonded joints are not relevant anymore (Ghafoori 2015). Moreover, strengthening using un-bonded systems does not require surface preparation of the metallic substrate, which reduces the overall time of onsite retrofitting. The authors have done a series of studies to compare the flexural performance of metallic beams strengthened by bonded and un-bonded CFRP laminates (Ghafoori and Motavalli 2015b, Ghafoori and Motavalli 2015c).

In this paper, a new system of un-bonded CFRP strengthening is presented wherein conventional gluing and bonding of the CFRP to the existing steel members is not required. A method based on the constant life diagram (CLD) is proposed for predicting the minimum CFRP pre-stress level required to prevent fatigue crack initiation in metallic girders (Ghafoori et al. 2015a). The paper begins by describing background related to the CLD method, after which strengthening of a Swiss historic bridge, the Münchenstein bridge, is discussed. Following measurements from the wireless sensor network (WSN) system are presented and conclusions given on strengthening of existing bridges using the new PUR system.

\section{FATIGUE RETROFIT THEORY}

In this section, a proactive design approach based on the CLD approach for fatigue strengthening of metallic members is developed. The proposed design approach is capable of taking into account the combined effect of alternating and mean stress magnitudes. Analytical models are developed to predict the fatigue resistance of retrofitted metallic girders.

CLDs can foresee the fatigue life of metals at different mean stress levels. For a given maximum stress $\left(\sigma_{\max }\right)$ and minimum stress $\left(\sigma_{\min }\right)$ in a sample stress history, the stress amplitude $\left(\sigma_{\mathrm{a}}\right)$ and the mean stress $\left(\sigma_{\mathrm{m}}\right)$ can be shown in the CLD diagram. The authors have described the half-plane CLD regions and different fatigue criteria for the design of metallic members in their earlier works (Ghafoori et al. 2015b, Ghafoori et al. 2015a, Ghafoori et al. 2015c). Based on the results of many laboratory experiments, the modified-Goodman and the Smith criteria have been recommended for design of ductile metals, such as mild steel and wrought iron, and brittle metals, such as cast iron, respectively.

\subsection{Goodman Criterion}

Figure 1 shows the modified Goodman criterion, the modified Johnson criterion and the yielding lines. $S_{\mathrm{y}}, S_{\mathrm{ut}}$ and $\mathrm{S}_{\mathrm{e}}$ are the yield stress, ultimate tensile stress and fatigue endurance limit, respectively. Goodman proposed a straight line through $\sigma_{\mathrm{a}}=\mathrm{S}_{\mathrm{e}}$ and $\sigma_{\mathrm{m}}=\mathrm{S}_{\mathrm{ut}}$, which is a sufficiently conservative approach for the design of ductile metals. The modified Goodman line in the first quadrant (before yielding) is written as:

$\frac{\sigma_{a}}{S_{e}}+\frac{\sigma_{m}}{S_{u t}}=\frac{1}{n}$,

where $\sigma_{\mathrm{a}}$ and $\sigma_{\mathrm{m}}$ are the stresses at the critical location of the member (e.g., hole edges) and $n$ is the safety factor. If the fatigue stresses $\left(\sigma_{a}\right.$ and $\left.\sigma_{b}\right)$ remain outside of the modified Goodman line, highlighted by blue in Figure 1, the member has finite fatigue life, while stresses inside this region have infinite life and are safe against fatigue. The results of lengthy fatigue tests have shown that the fatigue endurance limit is estimated as:

$S_{e}^{\prime}=\left\{\begin{array}{ll}0.5 S_{u t}, & S_{u t} \leq 1400 \mathrm{MPa} \\ 700 \mathrm{MPa}, & S_{u t}>1400 \mathrm{MPa}\end{array}\right.$ for steel

and for wrought irons, the endurance limit can be approximated as:

$S_{e}^{\prime}=0.55 S_{u t}$ for wrought iron

Therefore, Marin developed different parameters to quantify the influence of the size, surface conditions, loading and temperature. The Marin equation was obtained through statistical analysis and is written as:

$$
S_{e}=k_{a} k_{b} k_{c} k_{d} k_{e} S_{e}^{\prime},
$$

where $\mathrm{k}_{\mathrm{a}}, \mathrm{k}_{\mathrm{b}}, \mathrm{k}_{\mathrm{c}}, \mathrm{k}_{\mathrm{d}}$ and $\mathrm{k}_{\mathrm{e}}$ are, respectively, the surface condition, size, load, temperature and reliability modification factors. $S_{e}$ is the endurance limit at the critical location of the metallic member in condition and geometry of use. The procedure to calculate the Marin factors for this bridge is described in an earlier study (Ghafoori et al. 2015b).

\subsection{Johnson criterion}

Johnson (Johnson 1897) presented a formula in terms of $\mathrm{R}$ and $\sigma_{\max }$ for dimensioning metallic members as: 
$\sigma_{\max }=\frac{S_{u t}}{2-R} . \quad-1 \leq \mathrm{R} \leq 1$

Considering the dynamic effects in the case of bridge structures, the elements are subjected to shocks and vibrations due to the moving mass commonly called an 'impact'. Johnson has shown that Equation (5) is capable of taking into account the effect of both fatigue and impact. Equation (8) is in terms of $\mathrm{R}$ and $\sigma_{\max }$, however the authors (Ghafoori et al. 2015b) have shown that it is possible to formulate it in terms of $\sigma_{\mathrm{a}}$ and $\sigma_{\mathrm{m}}$ and plot it in CLD:

$\frac{\sigma_{a}}{\left(\frac{S_{u t}}{3}\right)}+\frac{\sigma_{m}}{S_{u t}}=\frac{1}{n} . \quad-1 \leq \mathrm{R} \leq 1$

\subsection{Goodman versus Johnson}

Comparing the Johnson formula presented in Equation (6) and the Goodman formula in Equation (1), it is seen that by setting the endurance limit to one third of tensile strength $\left(S_{e}=S_{u t} / 3\right)$, the Goodman equation becomes the Johnson equation. Practically, it is possible to use any of these two formulations for design of ductile metallic members. The advantage of using Johnson formula is that it works with the minimum knowledge about the existing metal and needs only the tensile strength $\left(\mathrm{S}_{\mathrm{ut}}\right)$. Although, in general, the modified Goodman criterion is more accurate, it needs much knowledge in order to calculate different Marin factors required for determination of $S_{e}$. When sufficient knowledge about the existing metallic girder and its production procedure are known, the modified Goodman formula is recommended for fatigue design. When such information is lacking, the modified Johnson formulation can be used.

\subsection{Calculation of CFRP pre-stress level to prevent fatigue crack initiation}

Assume that the stresses due to the external fatigue load, F, at the bottom flange of the metallic girder (see Fig. 2) before strengthening are $\sigma_{m^{*}}$ and $\sigma_{a^{*}}$ and corresponds to point $\mathrm{A}$ in Figure 1. In this section, the minimum CFRP pre-stress level by which the stresses in metal are shifted from point A ('at risk' zone) to point B ('safe' zone) is determined. Based on Figure 1, the magnitude of the required compressive stress in the beam bottom flange to shift the stresses on the Goodman line is written as

$\Delta \sigma_{m}=\sigma_{m^{*}}-\sigma_{m^{* *}}$,

where $\sigma_{m^{* *}}$ is obtained by rewriting Equation (1) in term of mean stress level as $\sigma_{m^{* *}}=\frac{S_{u t}}{n}-\frac{S_{u t} \sigma_{a^{*}}}{S_{e}}$

Note that here it is assumed that the stress range does not change after strengthening. It is because the medium modulus CFRP plates (with a modulus of elasticity less than that of steel) are used; thus, the increase in the stiffness of the metallic member is negligible, and an insignificant decrease in the stress range is expected. Substituting Equation (8) into Equation (7) gives

$\Delta \sigma_{m}=\sigma_{m^{*}}+\frac{\sigma_{a^{*}}}{S_{e}} S_{u t}-\frac{S_{u t}}{n}$,

where $\Delta \sigma_{m}$ is the minimum required compressive stress to shift the working stresses from point $A$ to point $\mathrm{B}$, as shown in Figure 1 .

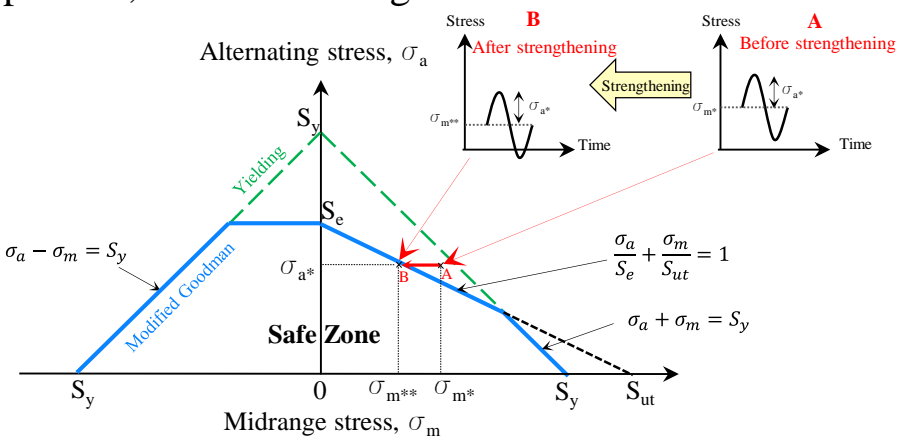

Figure 1. Presentation of CLD approach for fatigue strengthening. Effect of using a pre-stressed element is shown.

The minimum pre-stress force $\left(\mathrm{F}_{\text {pre }}\right)$ in the CFRP plate can be estimated using a cross-section analysis as

$\Delta \sigma_{m}=\frac{e F_{p r e} h}{2 I_{m}}+\frac{F_{p r e}}{A_{m}}$,

where $\mathrm{h}, \mathrm{A}$ and I are the height, the cross-sectional area and the moment of inertia of the metallic beam. $\mathrm{e}$ is the eccentricity between the CFRP plate and the beam neutral axis and is shown in Figure 2. Rearranging Equation (10) in terms of $F_{\text {pre }}$ gives

$$
F_{p r e}=\frac{\Delta \sigma_{m}}{\frac{h e}{2 I_{m}}+\frac{1}{A_{m}}} .
$$

Substituting Equation (9) into Equation (11) yields to

$$
\sigma_{p r e}=\frac{\sigma_{m^{*}}+\frac{\sigma_{a^{*}}}{S_{e}} S_{u t}-\frac{S_{u t}}{n}}{\left(\frac{h e}{2 I_{m}}+\frac{1}{A_{m}}\right) A_{p}},
$$

where $A_{p}$ is the net cross-sectional area of the CFRP plates and $\sigma_{\text {pre }}$ is the required CFRP pre-stress to have an infinite fatigue life for the metal. If the same procedure is implemented using the Johnson failure criterion (i.e., by using Eq. (6)), it would result in 
$\sigma_{p r e}=\frac{\sigma_{m^{*}}+3 \sigma_{a^{*}}-\frac{S_{u t}}{n}}{\left(\frac{h e}{2 I_{m}}+\frac{1}{A_{m}}\right) A_{p}}$.

Note that the method described in this paper is only to prevent fatigue crack initiation. However, when the bridge element has already cracked (prior to strengthening), a fracture mechanics based model that has been proposed previously by the authors (Ghafoori and Motavalli 2011, Ghafoori et al. 2012a, Ghafoori et al. 2012b) can be used to determine the required CFRP pre-stressing level needed to arrest the fatigue crack propagation in the metal. Non-destructive testing (NDT) inspections can provide evidences of the state of bridge elements, and help bridge authorities to choose the right strengthening scheme.
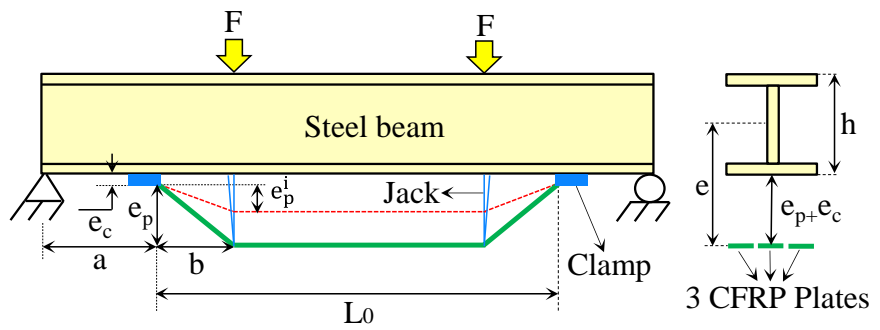

Figure 2. Scheme of a steel girder retrofitted by the PUR system.

Assume a metallic girder as shown in Figure 2. At the beginning of the strengthening, the CFRP plates are placed and tightened into the friction clamps without any tension. Due to the self-weight of the CFRP plates, they are deflected slightly downward and have an initial eccentricity of $e_{p}^{i}$ from the line connecting the two clamps. The initial eccentricity between the CFRP plate and beam bottom flange is equal to $e_{c}+e_{p}^{i}$, where $e_{c}$ is the height of the clamp. Using a jack, the eccentricity is increased from the initial value of $e_{p}^{i}$ to $e_{p}$; therefore, it increases the CFRP pre-stress level to $\sigma_{\text {pre }}$. The magnitude of CFRP plates eccentricity can be approximated by solving the third order polynomial in terms of $e_{p}$

$\left(\frac{h}{4 I_{m} B}\right) e_{p}^{3}+\frac{1}{2 B}\left(\frac{h e_{c}+0.5 h^{2}}{2 I_{m}}+\frac{1}{A_{m}}\right) e_{p}^{2}$

$+\frac{h}{2 I_{m}}\left(B-\sqrt{B^{2}+e_{p}^{i 2}}\right) e_{p}=\gamma$,

where

$$
\begin{aligned}
& \gamma=\left(\sigma_{m^{*}}+3 \sigma_{a^{*}}-\frac{S_{u t}}{n}\right)\left(\frac{0.5 C+\sqrt{B^{2}+e_{p}^{i 2}}}{A_{p} E_{p}}\right)+ \\
& \left(\frac{h e_{c}+0.5 h^{2}}{2 I_{m}}+\frac{1}{A_{m}}\right)\left(\sqrt{B^{2}+e_{p}^{i 2}}-B\right)
\end{aligned}
$$

More information about development of Equation 15 can be found in the author's previous work (Ghafoori et al. 2015b). Both theories (Goodman and Johnson) provide design reference values for old structural elements. Discussion on a methodology to account the damage due to cycles applied before strengthening has been given in(Ghafoori et al. 2015a).

\section{RETROFITTING OF THE}

\section{MÜNCHENSTEIN RAILWAY BRIDGE}

The Münchenstein Bridge was constructed in 1875 by G. Eiffel, who later built the Eiffel Tower in Paris. The bridge is located near Basel City over the river Birs in Switzerland. In 1891, after 15 years of service, the bridge suddenly collapsed when a passenger train was passing across it. The disaster took the lives of 73 passengers and is historically the worst railway accident ever in Switzerland.

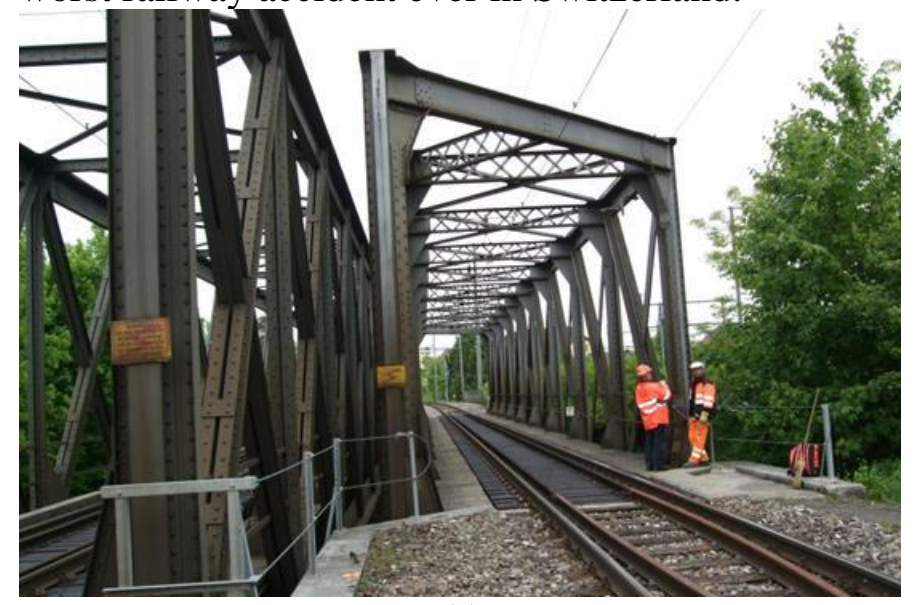

(a)

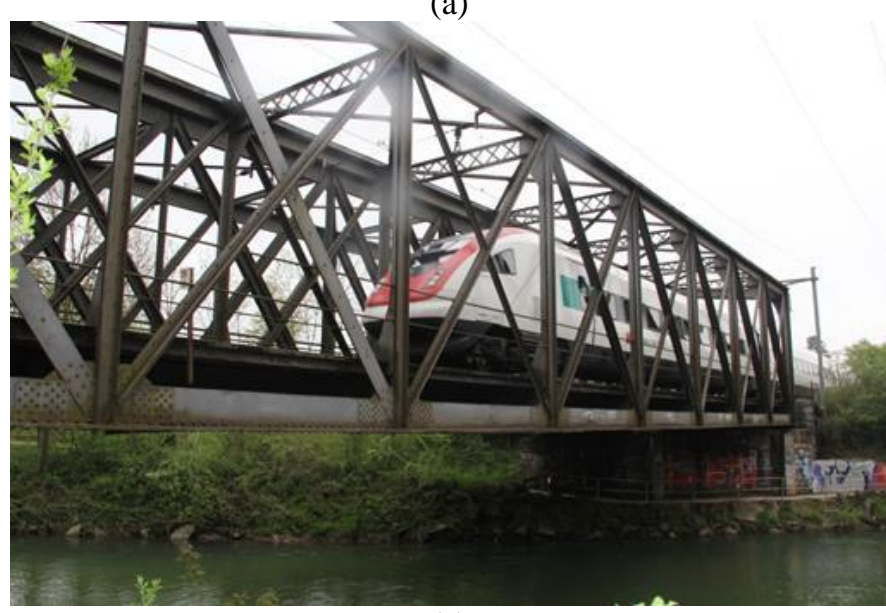

(a)

Figure 3. (a) Münchenstein railway bridge, (b) it consists of 10 panels with the total length of $45.2 \mathrm{~m}$, width of $5 \mathrm{~m}$ and height of $6.15 \mathrm{~m}$, built on a 45 -degrees skew over a river.

A single-span riveted bridge was then constructed in 1892 , as a replacement for the collapsed one. The bridge, as shown in Figure 3, consists of 10 frames and was constructed approximately $5 \mathrm{~m}$ above the water level. The total length of the bridge is approximately $45.2 \mathrm{~m}$. The bridge is subjected daily to both passenger and freight trains. The bridge consists of two main girders connected by various cross-beams, stringers and lateral bracings, as shown in Figure 4. Prior to the application of the PUR system on the bridge, the system was subjected to different loading 
patterns to examine the static and fatigue performance (Ghafoori and Motavalli 2015a).

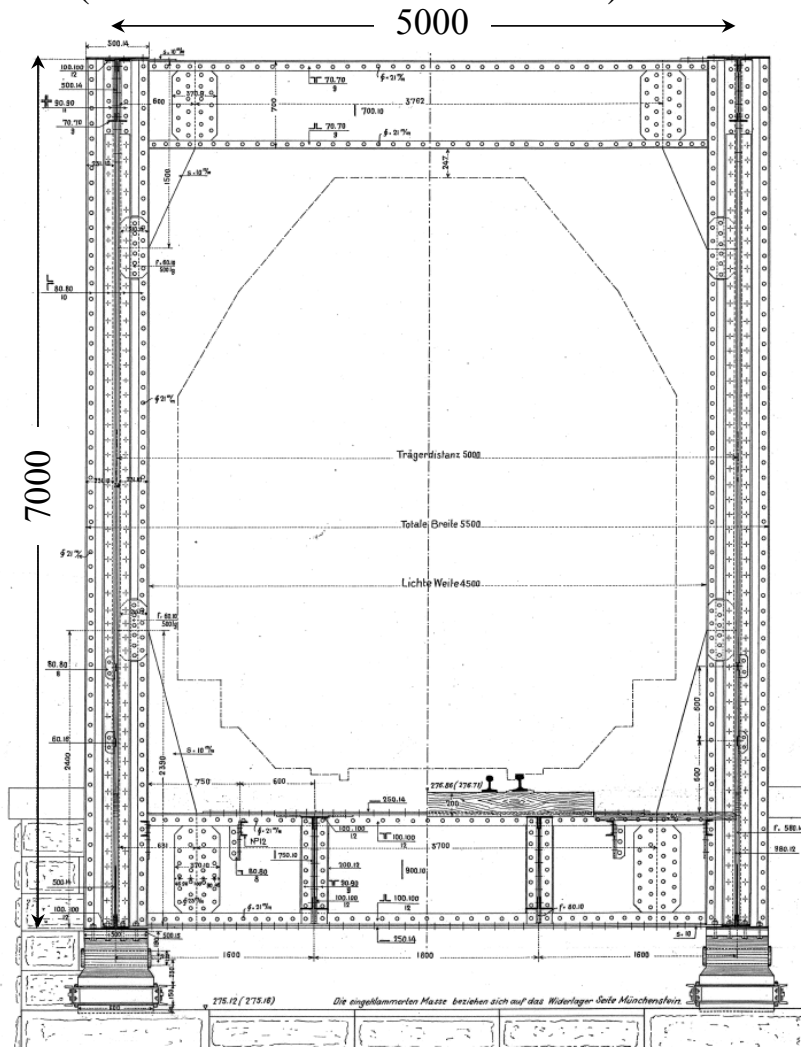

Figure 4. Original drawing of the bridge riveted frames (dimensions are in $\mathrm{mm}$ ).

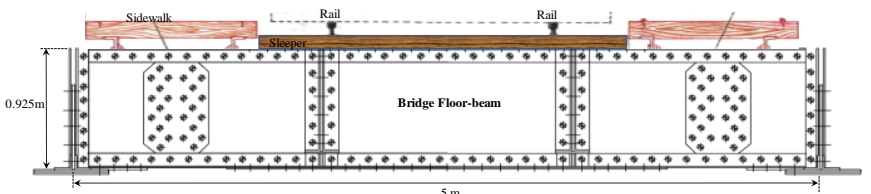

Figure 5. Dimensions of the bridge floor-beams (cross-beams) in $\mathrm{m}$.

A total of four identical steel beams were tested, including one un-strengthened beam and three strengthened beams, in a modified staircase method. Moreover, the developed PUR system performed well during the fatigue testing, surviving more than $33,000,000$ cycles without any damage or sliding in the friction clamps. More details about experimental program and the test results can be found in authors' previous publication (Ghafoori et al. 2015a).

\subsection{Retrofitting of the bridge and measurements}

Based on the Swisscode (SIA 263:2003), a freight train load model D4 has to be used for fatigue verification. Applying the D4 load model as the live load and also considering the dead load in the FE model, the stresses at the bottom flanges of the cross-beams were obtained. After applying the relevant stress concentration factor, $\sigma_{m^{*}}$ and $\sigma_{a^{*}}$ stresses of 82.5 $\mathrm{MPa}$ and $91.1 \mathrm{MPa}$, respectively, in bottom flange of the fifth cross-beam were obtained. Furthermore, considering Figures 4 and 5, the following parameters were used for the strengthening of the fifth cross-beam:
$\mathrm{A}=825 \mathrm{~mm}, B=825 \mathrm{~mm}, C=1700 \mathrm{~mm}$,

$L_{0}=3350 m m, \mathrm{e}_{\mathrm{p}}^{\mathrm{i}}=77 \mathrm{~mm}, \mathrm{e}_{\mathrm{c}}=55 \mathrm{~mm}, \mathrm{~h}=925 \mathrm{~mm}$.

Based on Equation (6), considering a safety factor of $n=1.04$, a pre-stress level of approximately $34.5 \%$ is determined for strengthening using the Johnson criterion. Once the friction clamps were mounted on the cross-beam and the CFRP plates were fixed into the clamps, an initial eccentricity of $e_{p}^{i}=77 \mathrm{~mm}$ was observed. Thus, for an initial value of $e_{p}^{i}=77$ $\mathrm{mm}$, an eccentricity of $\mathrm{e}_{\mathrm{p}}=142 \mathrm{~mm}$ was required to gain $34.5 \%$ pre-stress in CFRP plates. A finite element (FE) model of the bridge was created and analyzed using ABAQUS. The model geometry is based on the construction documents of the Münchenstein Bridge. More details about FE modeling and verifications can be found in (Ghafoori et al. 2014).

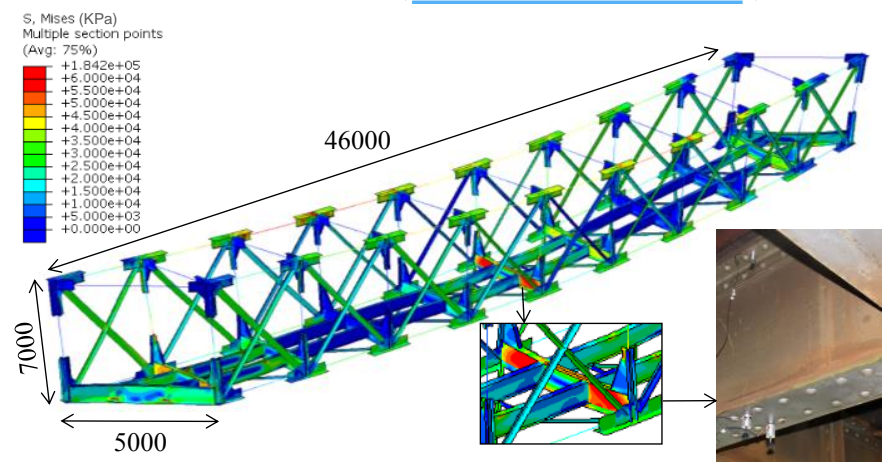

Figure 6. The results of the FE model of the bridge were compared with field measurements.

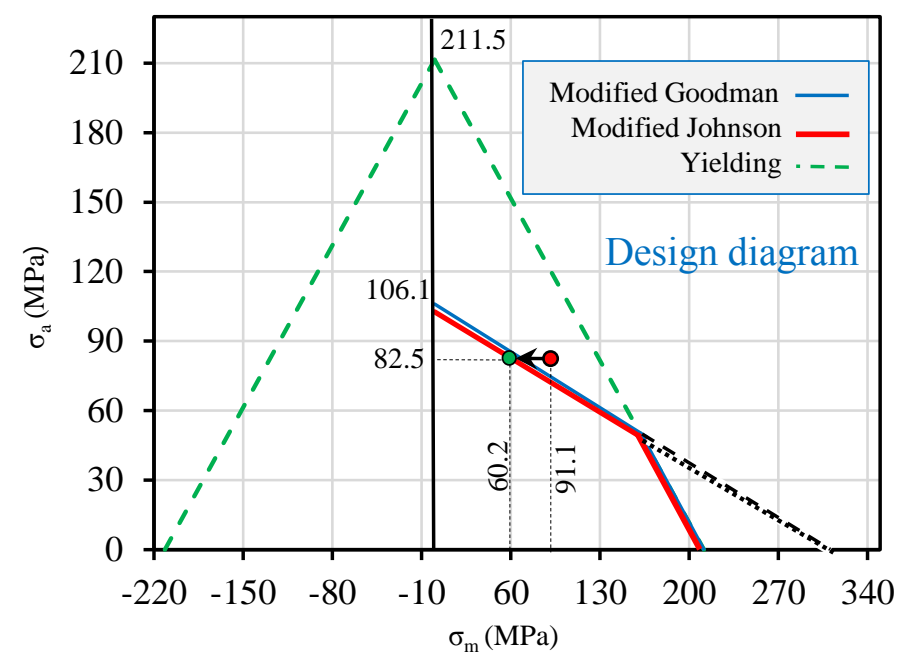

Figure 7. Shifting the stresses in the critical sport from the risk to the safe life regime according the presented on the modified Goodman and the modified Johnson criteria.

During the on-site strengthening, a jack is used to increase the eccentricity between the CFRP plates and the beam; thus, the CFRP pre-stress level and the magnitude of the compressive stress at the rivet holes increase. The strain on the CFRP plate and the metallic beam are measured using the glued and magnetic strain gauges, respectively. The procedure of pre-stressing the CFRP plates took approximately 30 minutes, and during this time, trains were crossing the bridge. The two sudden jumps in the stress at 
the bottom flange of the beam indicate the passage of two passenger trains.

Figure 7 shows the stresses in the flange before and after strengthening in CLD. This figure shows that the modified Goodman and the modified Johnson formulas show very similar fatigue behavior. Note that although calculation of the endurance limit, $S_{\mathrm{e}}$, for the Goodman criterion required a lot of knowledge about the cross-beam, ultimately, the predictions of both criteria are very similar. According to Figure 7, the modified Johnson criterion is slightly more conservative than the modified Goodman criterion, and it is used for the design in this paper. In Figure 7, it is observed that the stresses are shifted to the safe region based on both the modified Goodman and modified Johnson criteria. Figure 8 schematically shows the different components of the retrofit system.

The friction clamp consists of a lower plate, a middle plate and two upper plates. Three CFRP plates are gripped between the lower plate and the middle plate due to the compressive force imposed by the pre-stressed bolts. The lower flange of the beam is also gripped between the middle plate and the upper plate due to the compressive force provided by the pre-stressed bolts.
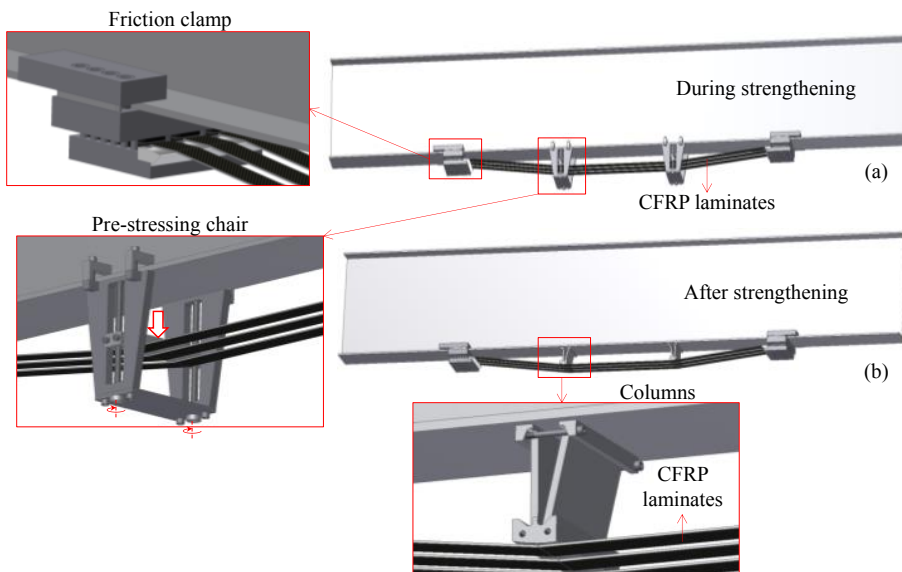

Figure 8. Various parts of the retrofit system: (a) the prestressing chair has a saddle that pushes the CFRP plates away from the beam and (b) when the required eccentricity is reached, a column is placed between the CFRP plates and the saddle. The system has been patented by S\&P AG (Ghafoori and Motavalli 2013b).

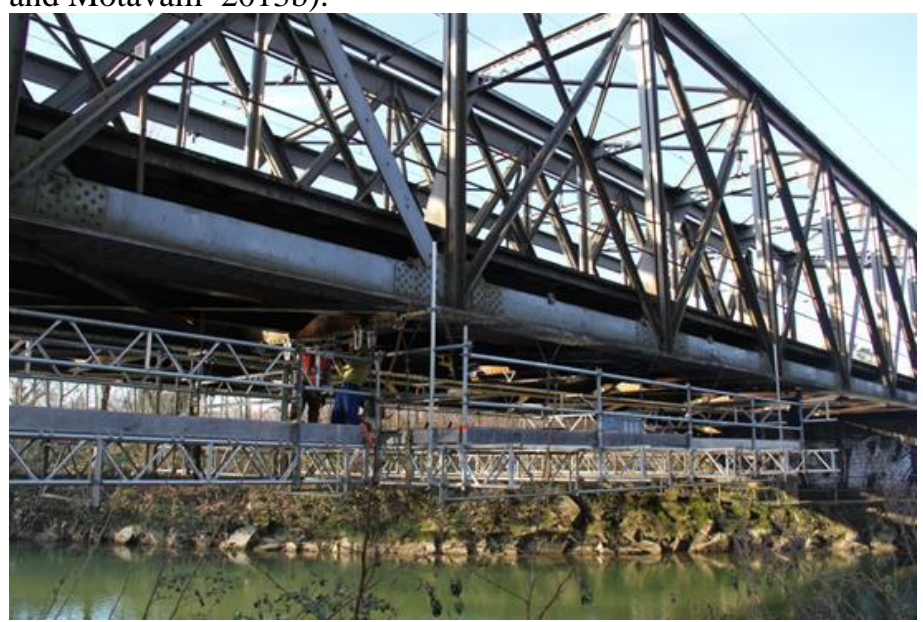

(a)

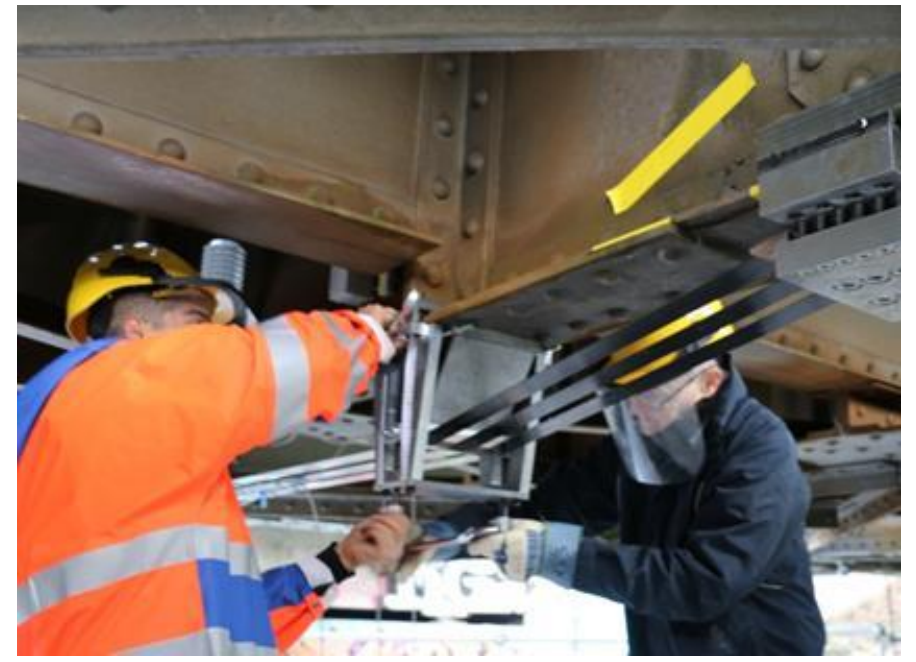

(b)

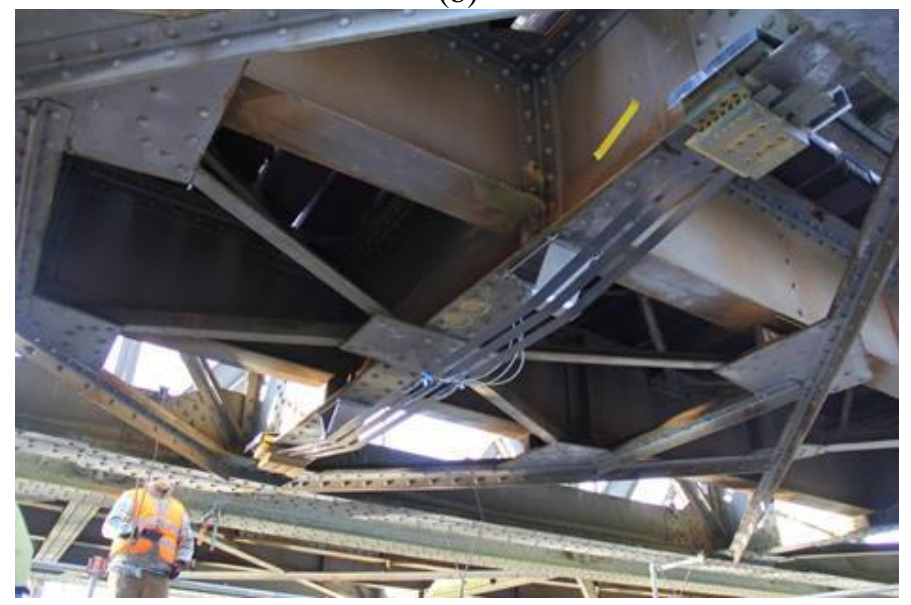

(c)

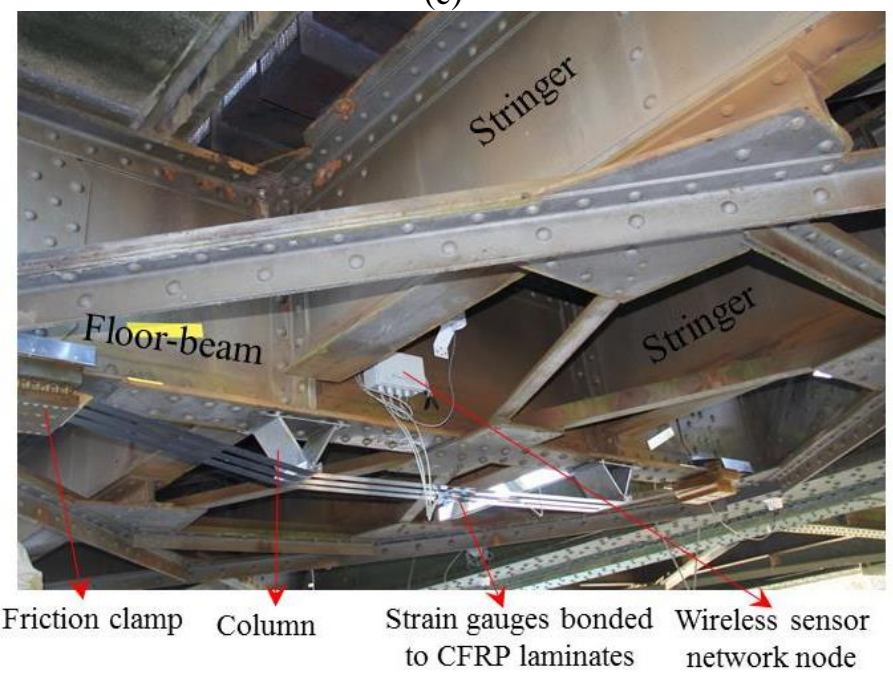

(d)

Figure 9. Retrofitting procedure of Münchenstein Bridge: (a) setting up a scaffolding, (b) mounting the clamps with the laminates on the beam and applying eccentricity between the CFRP plates and the beam using a pre-stressing chair (c) inserting the columns and removing the chair (d) monitoring using wireless sensor network system.

The pre-stressing chair consists of a saddle that is guided along two threaded bars. The position of the saddle with respect to the beam can be adjusted by turning the threaded rods, as shown in Figure 8.a. By turning the threaded rods, the saddle moves downward and pushes the CFRP plates downward. 
Once the required eccentricity between the CFRP plates and the beam is achieved, two column plates are inserted between the saddle and the beam and the pre-stressing chair is removed. Each column plate is placed into a column shoe, as shown in Figure 8.b. Note that the system does not require any welding or drilling holes in the existing structure. The system can be disassembled and removed from the bridge (if necessary) without any residual effects on the existing bridge.

More details about the design of the friction clamps, columns and saddle can be found in (Ghafoori and Motavalli 2015a). Figure 10 shows the stress timehistory at the mid-span of the bottom flange of the fifth cross-beam before and after strengthening due to the passage of an $\mathrm{S} 3$ passenger train.

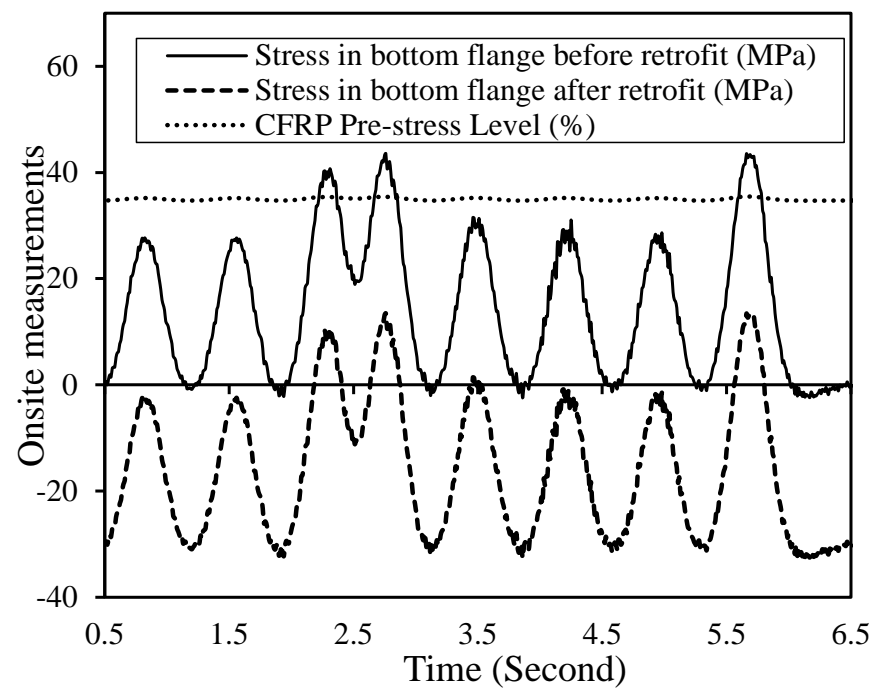

Figure 10. Stresses in the bottom flange of the bridge floorbeam due to the passages of an S3 train before and after strengthening.

Note that the dead load is not included in this measurement because the strain gauges are only sensitive to live loads. The amplitude of the fluctuating stresses in the CFRP plates due to train passage is small (approximately 0.7\%). Figure 10 shows that the stress range does not change before and after strengthening, which confirms the validity of the assumption made in this paper. Note that the bridge is subjected to different types of trains, including passenger and freight trains. The design of the strengthening system was based on a D4 freight train load model because the mean stress level still remains in the tension zone after strengthening (see Fig. 7).

To ensure no slip occurs between the CFRP plates and the clamps and also between the friction clamps and the metallic beams, one strain gauge was glued on each CFRP plate, as shown in Figure 9. The longterm behavior of CFRP laminates have been studied through deployment of wireless sensor network (WSN) system. Using the WSN system, the strains along CFRP laminates were read for almost one year to ensure the retrofit system functions properly.

\section{CONCLUSIONS}

Analytical formulations based on the CLD method were introduced to predict the minimum CFRP prestress levels required to prevent fatigue crack initiation in the metal. Furthermore, a pre-stressed unbonded CFRP retrofit system was developed and used for fatigue strengthening of a 120-year-old metallic railway bridge in Switzerland.

1) It was shown that by applying a pre-stress force to an existing fatigue-susceptible detail, the mean stress level (and the stress ratio) can be reduced such that the detail is shifted from the finite life regime to the infinite life regime. The method is particularly valuable when the stress history due to prior traffic loading cannot be easily determined.

2) It was shown that although the modified Goodman criterion requires extensive knowledge about the materials within the existing metallic girder, it resulted in nearly the same fatigue assessment as that determined by the modified Johnson formula which requires little a-priori material knowledge.

3) According to many structural codes, the stress range is the main parameter that affects the fatigue life of a metallic member. A major deficiency related to this method is that it does not consider the mean stress effect for stress ratios of $0<R<1$ (i.e., tension-tension stresses). Both the modified Johnson and the modified Goodman criteria reflect the combined effects of the stress range, mean stress level and material properties. The suggested modified Johnson formula is easy to apply and needs only the ultimate tensile strength as the input parameter, which makes the method suitable for design purposes.

\section{ACKNOWLEDGMENTS}

This research was funded by the Swiss Commission of Technology and Innovation. The authors would also like to thank Ms. Carolina Boschmann and the technicians of the Empa. Financial and technological support from the S\&P Clever Reinforcement AG Company and the Swiss Federal Railways (SBB) are also acknowledged.

\section{PREFERENCES}

Al-Emrani, M. \& Kliger, R. 2006a. Analysis of interfacial shear stresses in beams strengthened with bonded prestressed laminates. Composites - Part B, 37, 265-272.

Al-Emrani, M. \& Kliger, R. 2006b. Experimental and numerical investigation of the behaviour and strength of composite steel-CFRP members. Advances in structural engineering, 9, 819-831.

Al-Emrani, M. \& Kliger, R. 2009. Fatigue prone details in steel bridges. Proceedings of Nordic Steel Construction Conference. 
Benachour, A., Benyoucef, S., Tounsi, A. \& Adda Bedia, E. A. 2008. Interfacial stress analysis of steel beams reinforced with bonded prestressed plates. Engineering Structures, 30, 3305-3315.

Colombi, P., Bassetti, A. \& Nussbaumer, A. 2003a. Analysis of cracked steel members reinforced by pre-stress composite patch. Fatigue and Fracture of Engineering Materials and Structures, 26, 59-66.

Colombi, P., Bassetti, A. \& Nussbaumer, A. 2003b. Crack growth induced delamination on steel members reinforced by prestressed composite patch. Fatigue Fract Engng Mater Struct, 26, 429-437.

Czaderski, C. \& Rabinovitch, O. 2010. Structural behavior and interlayer displacements in CFRP plated steel beams - Optical measurements, analysis, and comparative verification. Composites - Part B, 41, 276-286.

Dawood, M. \& Rizkalla, S. 2010. Environmental durability of a CFRP system for strengthening steel structures. Construction and Building Materials, 24, 1682-1689.

Dawood, M., Rizkalla, S. \& Sumner, E. 2007. Fatigue and overloading behavior of steel-concrete composite flexural members strengthened with high modulus CFRP materials. Journal of Composites for Construction, 11, 659-669.

El-Hacha, R. \& Aly, M. Y. E. 2013. Anchorage system to prestress FRP laminates for flexural strengthening of steel-concrete composite girders. Journal of Composites for Construction, 17, 324-335.

Ghafoori, E. 2013. Interfacial stresses in beams strengthened with bonded prestressed plates. Engineering Structures, 46, 508510.

Ghafoori, E. 2015. Fatigue strengthening of metallic members using un-bonded and bonded CFRP laminates. PhD Thesis, ETHZurich, http://dx.doi.org/10.3929/ethz-a-010453130.

Ghafoori, E. \& Motavalli, M. 2011. Analytical calculation of stress intensity factor of cracked steel I-beams with experimental analysis and 3D digital image correlation measurements. Engineering Fracture Mechanics, 78, 3226-3242.

Ghafoori, E. \& Motavalli, M. 2013a. Flexural and interfacial behavior of metallic beams strengthened by prestressed bonded plates. Composite Structures, 101, 22-34.

Ghafoori, E. \& Motavalli, M. 2013b. Verfahren zum Vorspannen eines Stahlbauwerkes sowie damit vorgespanntes Stahbauwerk. Swiss Patent CH 706630 B1, 14th May 2013.

Ghafoori, E. \& Motavalli, M. 2015a. Innovative CFRP Pre-stressing System for Strengthening of Metallic Structures. Journal of Composites for Construction, doi: http://dx.doi.org/10.1061/(ASCE)CC.1943-5614.0000559.

Ghafoori, E. \& Motavalli, M. 2015b. Lateral-torsional buckling of steel I-beams retrofitted by bonded and un-bonded CFRP laminates with different pre-stress levels: experimental and numerical study. Construction and Building Materials, 76, 194-206.

Ghafoori, E. \& Motavalli, M. 2015c. Normal, high and ultra-high modulus CFRP laminates for bonded and un-bonded strengthening of steel beams. Materials and Design, 67, 232-243.

Ghafoori, E., Motavalli, M., Botsis, J., Herwig, A. \& Galli, M. 2012a. Fatigue strengthening of damaged metallic beams using prestressed unbonded and bonded CFRP plates. International Journal of Fatigue, 44, 303-315.

Ghafoori, E., Motavalli, M., Nussbaumer, A., Herwig, A., Prinz, G. \& Fontana, M. 2015a. Determination of minimum CFRP prestress levels for fatigue crack prevention in retrofitted metallic beams. Engineering Structures, 84, 29-41.
Ghafoori, E., Motavalli, M., Nussbaumer, A., Herwig, A., Prinz, G. S. \& Fontana, M. 2015b. Design criterion for fatigue strengthening of riveted beams in a 120-year-old railway metallic bridge using pre-stressed CFRP plates. Composites Part B, 68, 1-13.

Ghafoori, E., Motavalli, M., Zhao, X. L., Nussbaumer, A. \& Fontana, M. 2015c. Fatigue design criteria for strengthening metallic beams with bonded CFRP plates. Engineering Structures, 101, 542-557.

Ghafoori, E., Prinz, G. S., Mayor, E., Nussbaumer, A., Motavalli, M., Herwig, A. \& Fontana, M. 2014. Finite element analysis for fatigue damage reduction in metallic riveted bridges using pre-stressed CFRP plates. Polymers, 6, 1096-1118.

Ghafoori, E., Schumacher, A. \& Motavalli, M. 2012b. Fatigue behavior of notched steel beams reinforced with bonded CFRP plates: Determination of prestressing level for crack arrest. Engineering Structures, 45, 270-283.

Johnson, J. B. 1897. The materials of construction, (1st ed.) John Wiley and Sons, New York, pp. 537-47.

Linghoff, D., Al-Emrani, M. \& Kliger, R. 2010. Performance of steel beams strengthened with CFRP laminate - Part 1: Laboratory tests. Composites - Part B, 41, 509-515.

Nozaka, K., Shield, C. \& Hajjar, J. 2005. Effective Bond Length of Carbon-Fiber-Reinforced Polymer Strips Bonded to Fatigued Steel Bridge I-Girders. Journal of Bridge Engineering, 10, 195-205.

Rizkalla, S., Dawood, M. \& Schnerch, D. 2008. Development of a carbon fiber reinforced polymer system for strengthening steel structures. Composites - Part A, 39, 388-397.

Saadatmanesh, H., Albrecht, P. \& Ayyub, B. M. 1989. Guidelines for flexural design of prestressed composite beams. Journal of structural engineering New York, N.Y., 115, 2944-2961.

Schnerch, D., Dawood, M., Rizkalla, S. \& Sumner, E. 2007. Proposed design guidelines for strengthening of steel bridges with FRP materials. Construction and Building Materials, 21, 1001-1010.

Schnerch, D., Dawood, M., Rizkalla, S., Sumner, E. \& Stanford, K. 2006. Bond behavior of CFRP strengthened steel structures. Advances in Structural Engineering, 9, 805-817.

Smith, S. T. \& J.G., T. 2001. Interfacial stresses in plated beams. Engineering Structures, 23, 851-71.

Tavakkolizadeh, M. \& Saadatmanesh, H. 2003. Repair of damaged steel-concrete composite girders using carbon fiberreinforced polymer sheets. Journal of Composites for Construction, 7, 311-322.

Wu, C., Zhao, X. L., Al-Mahaidi, R., Emdad, M. R. \& Duan, W. H. 2013. Fatigue tests on steel plates with longitudinal weld attachment strengthened by ultra high modulus carbon fibre reinforced polymer plate. Fatigue and Fracture of Engineering Materials and Structures, 36, 1027-1038.

Zhao, X. L., Bai, Y., Al-Mahaidi, R. \& Rizkalla, S. 2014. Effect of dynamic loading and environmental conditions on the bond between cfrp and steel: State-of-the-art review. Journal of Composites for Construction, 18. 